\title{
Low loss power splitter for antenna beam forming networks using probes in a waveguide
}

Dich, Mikael; Mortensen, Mette Dahl

Published in:

Proceedings of the 24th European Microwave Conference

Link to article, DOI:

10.1109/EUMA.1994.337479

Publication date:

1994

Document Version

Publisher's PDF, also known as Version of record

Link back to DTU Orbit

Citation (APA):

Dich, M., \& Mortensen, M. D. (1994). Low loss power splitter for antenna beam forming networks using probes in a waveguide. In Proceedings of the 24th European Microwave Conference (pp. 1791-1795). IEEE.

https://doi.org/10.1109/EUMA.1994.337479

\section{General rights}

Copyright and moral rights for the publications made accessible in the public portal are retained by the authors and/or other copyright owners and it is a condition of accessing publications that users recognise and abide by the legal requirements associated with these rights.

- Users may download and print one copy of any publication from the public portal for the purpose of private study or research.

- You may not further distribute the material or use it for any profit-making activity or commercial gain

- You may freely distribute the URL identifying the publication in the public portal

If you believe that this document breaches copyright please contact us providing details, and we will remove access to the work immediately and investigate your claim 


\title{
Low loss power splitter for antenna beam forming networks using probes in a waveguide
}

\author{
M. Dich and M. Dahl Mortensen \\ Electromagnetics Institute, Technical University of Denmark \\ Building 348, DK-2800 Lyngby, Denmark \\ Telephone +45 42881444 \\ Fax +4545931634
}

\section{ABSTRACT}

The design of a low loss one-to-four power splitter suitable for beam forming networks in antenna arrays is presented. The power splitter is constructed of a shorted waveguide in which five coaxial probes are inserted. Methods for the design of the power splitter are presented together with an experimental verification.

\section{INTRODUCTION}

Planar antennas of microstrip patches are often used for airborne radar applications. Such antennas often consist of several panels of microstrip patches. To feed the individual panels from a single input port, a power splitter is needed. The power splitter could be constructed using traditional microstrip components (branch-line couplers, Wilkinson power splitters etc.) but their losses are relatively high. In this paper a low loss power splitter, construced of a piece of shorted waveguide containing coaxial probes is presented. To design the power splitter both method of moments models and network models have been developed for the probe-to-waveguide components involved. Using these models, a four way power splitter with unequal split has been designed, manufactured and measured.

\section{THE POWER SPLITTER}

The designed power splitter, shown in Fig. 1, contains five coaxial probes. The input port is located in the center of the waveguide. To obtain the electrical characteristics of this probe, a method of moments (MM) model for a single probe inserted into a 


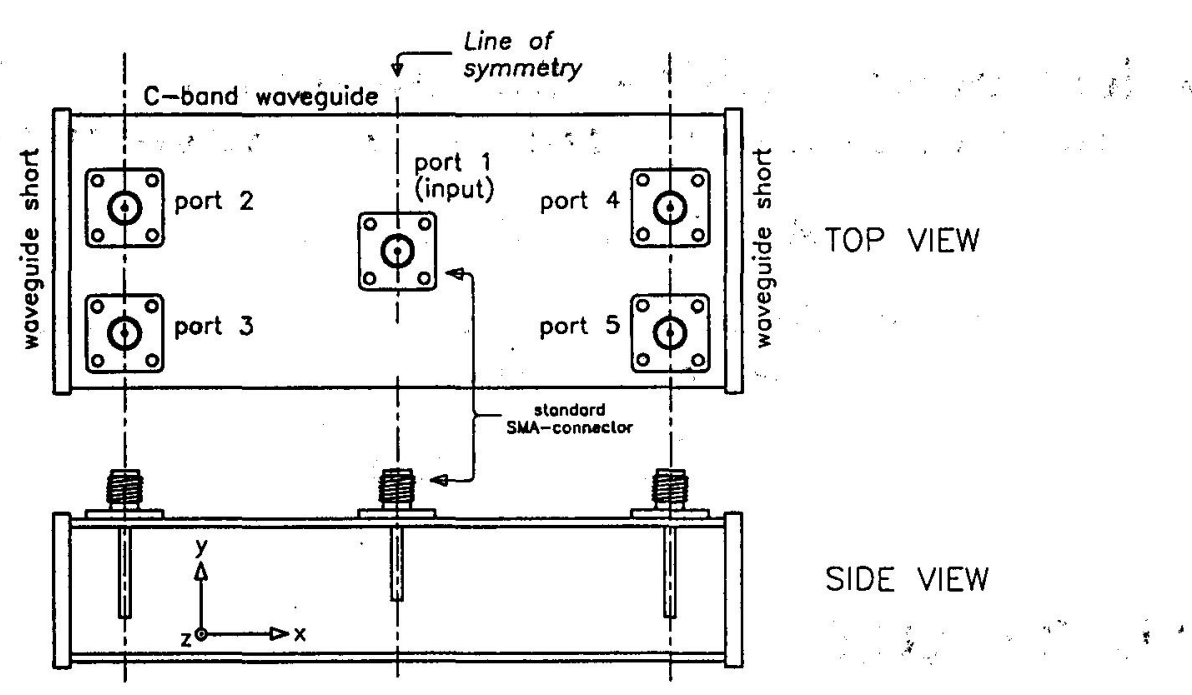

Figure 1: The four way power splitter

infinite waveguide has been developed. The four output ports are located in pairs near the shorted ends of the waveguide. To obtain the characteristics of these probes, a MM model for two closely spaced probes inserted into an semi-infinite waveguide has been developed. In calculating the scattering parameters of the entire power splitter a $\mathrm{TE}_{10}$-mode transmission line circuit as shown in Fig. 2 has been used.

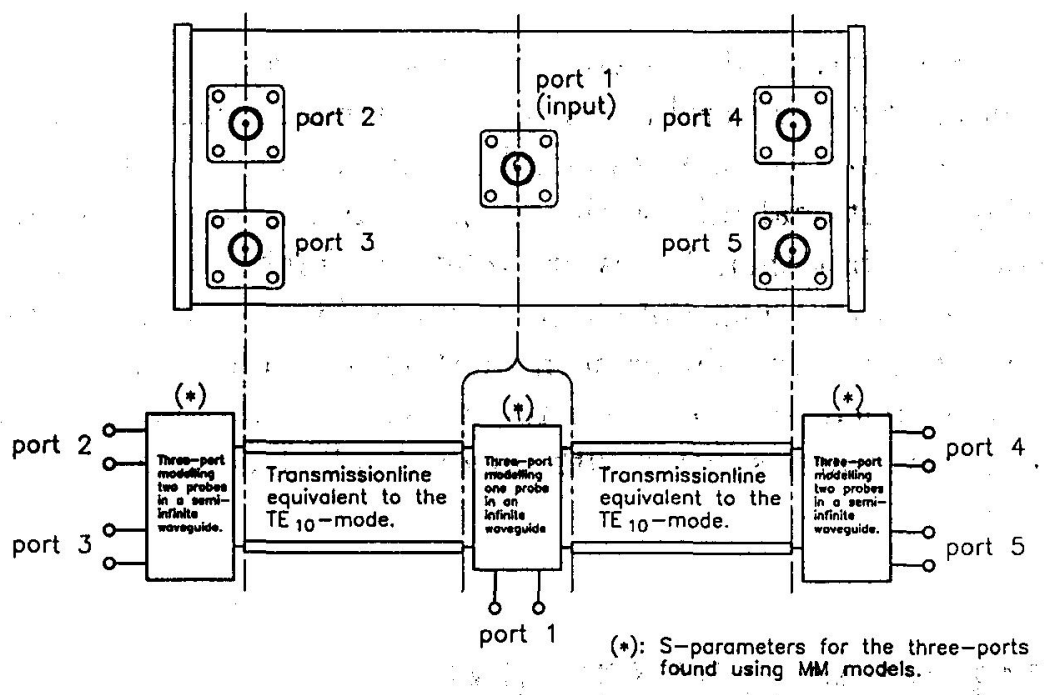

Figure 2: Model for the power splitter 


\section{THE METHOD OF MOMENTS MODEL}

The MM models of the probe-to-waveguide components are based on the work of Jarem [1]. The MM models use sinusodial functions for the expansion of the currents on the probe surface. Only the $y$-directed parts of the probe current is inoluded in the analysis and is approximated by ten filamentary currents equally spaced on the surface of the circular probe. The field scattered from the probe currents are found using the electrical Green's functions for a rectangular waveguide. The coaxial source is approximated by a magnetic frill current radiating into half space. Finally, the probe currents are found by requiring, in a Galerkin type of procedure, that the tangential electric field is zero in the center of the probe. Three different MM models have been programmed: one model for two closely spaced probes in a semi-infinite waveguide and models for a single probe in both a semi-infinite and an infinite waveguide.

\section{NETWORK MODELS}

Network models have been developed for the three types of probe-to-waveguide components. The network models make it more feasible to include the components in a microwave CAD program, since only three circuit elements are needed to describe each probe. The network model for a single probe in an semi-infinite waveguide is shown in Fig. 3. The values for the circuit elements can be found from the scattering parameters using simple expressions.

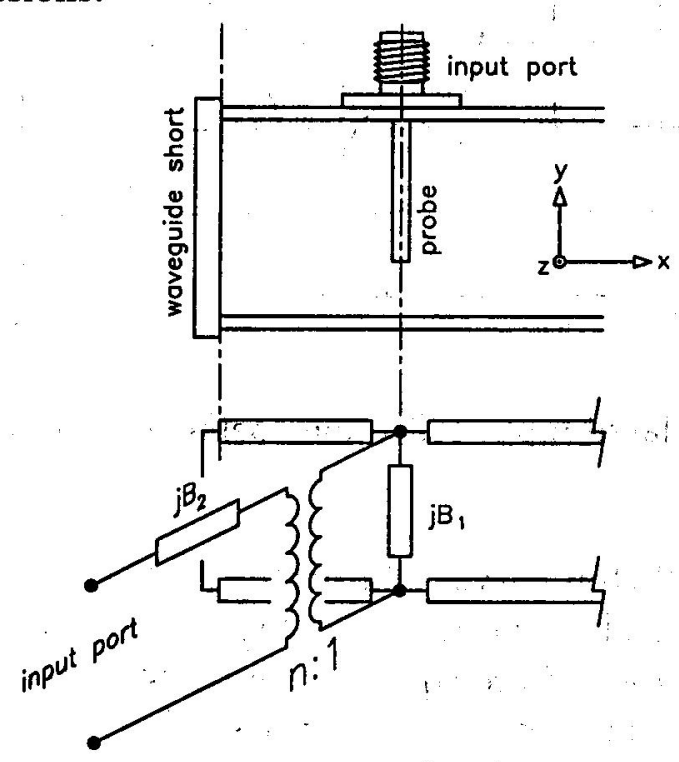

Figure 3: Network model for a probe in a semi-infinite waveguide 


\section{EXPERIMENTAL RESULTS}

To test the performance of both the MM models and the network models, the four way power splitter was designed using the transmission line circuit show in Fig. 2. Since the power splitter is intended for a microstrip antenna used in a specific SAR radar system, the power splitter was designed with unequal split. The level of the output of two of the output ports (ports 3 and 5) are designed to be $70 \%$ of the level of the output of the remaining two ports (ports 2 and 4). The input reflection of the input port (port 1) is designed to be as low as possible in the frequency band of operation: $5.3 \mathrm{GHz} \pm 50$ $\mathrm{MHz}$. The power splitter was manufactured from standard C-band waveguide and the probes are standard SMA-connectors with long center conductors.

In Fig. 4 the input reflection coefficients of the input port is shown when all the output ports are matched. The solid curve represents the calculated input reflection coefficient and the dashed curve the measured. In Fig. 5 the transmission coefficients between the

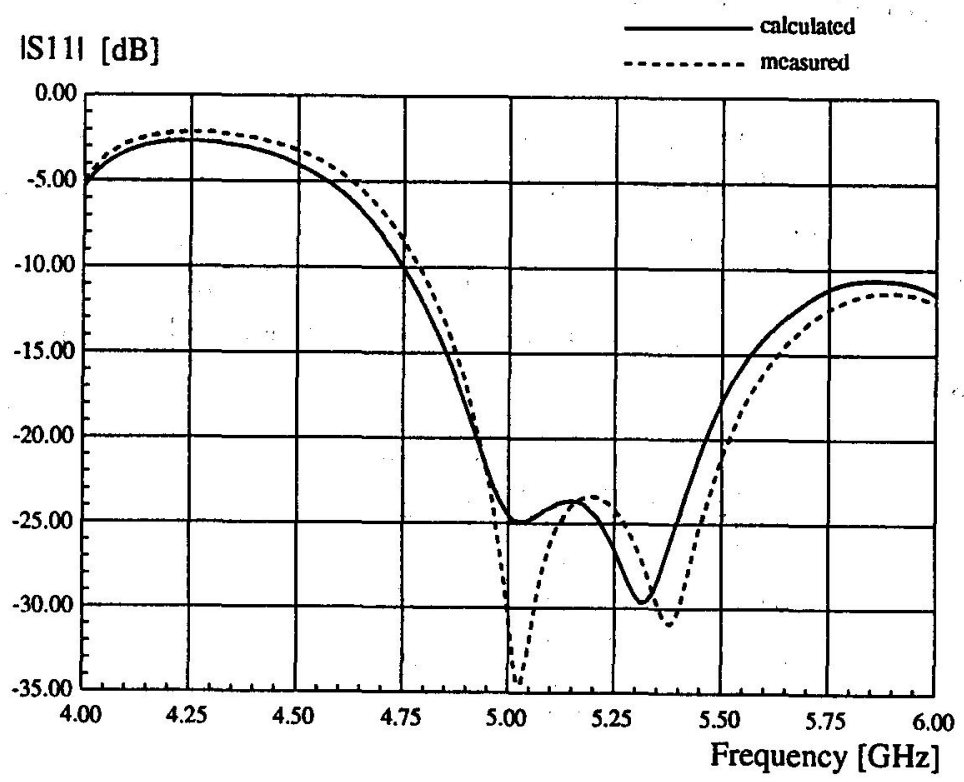

Figure 4: Measured and calculated input reflection coefficient for the experimental four way power splitter

input port (port 1) and port 2 (top curve) and port 3 (bottom curve) is shown. Since the power splitter is symmetrical as indicated on Fig. 1, the transmission coefficients between port 1 and the ports 4 and 5 are equal to the transmission coefficients between port 1 and the ports 2 and 3 . The loss of the power splitter has been measured to be less than $0.1 \mathrm{~dB}$ in the frequnecy band $5.3 \mathrm{GHz} \pm 100 \mathrm{MHz}$. 


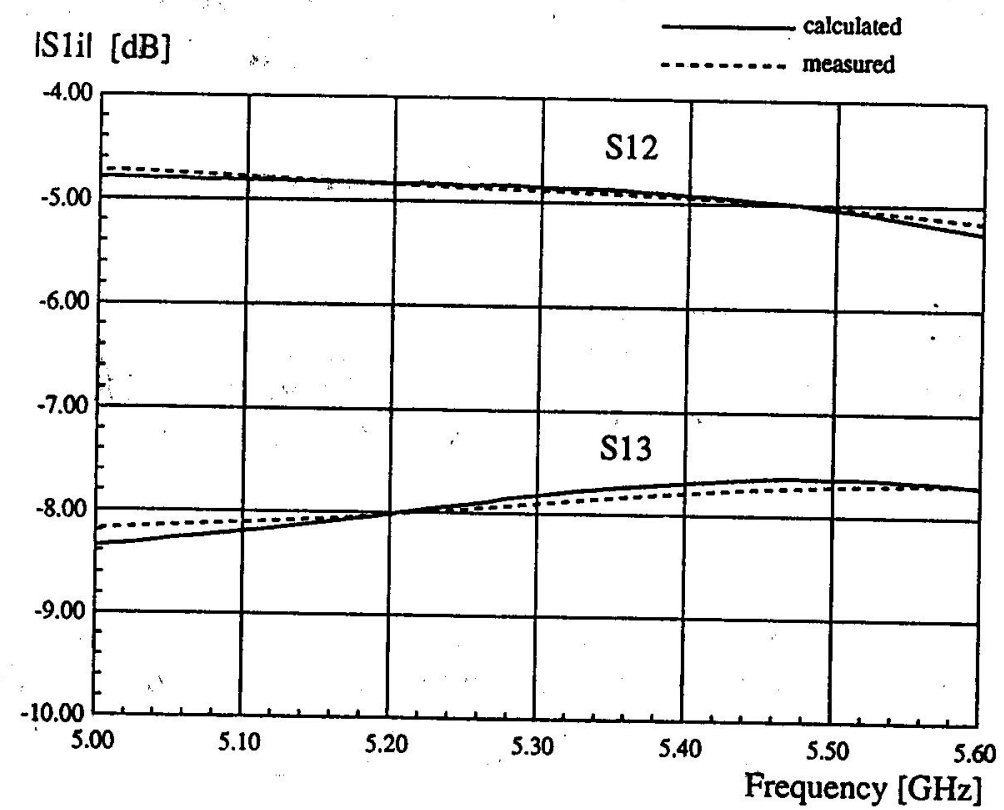

Figure 5: Measured and calculated transmission coefficients for the experimental four way power splitter

\section{CONCLUSION}

In conclusion, we have demonstrated that a shorted waveguide, in which probes are inserted, can be used as a low loss power splitter. A Method of Moments (MM) model has been developed for the relevant configurations of probes in a perfectly electrically conducting (PEC) waveguide. The power splitter was designed using results computed from the.MM model and was subsequently manufactured and measured. The predicted characteristics of the power splitter are in excellent agreement with the measured data. Further, it has been experimentally verified that the designed power splitter possess low losses.

\section{References}

[1] J. M. Jarem, "A Multifilament Method-of-Moments Solution for the Input Impedance of a Probe-Excited Semi-Infinite Waveguide", IEEE Transactions on Microwave Theory and Techniques, 35(1), pp. 14-19, January 1987. 